\title{
Maximum allowable pressure during heavy slurry displacement
}

\author{
Abdeslem Leksir $^{1}$ \\ Received: 30 March 2020 / Accepted: 13 July 2020 / Published online: 23 July 2020 \\ (c) The Author(s) 2020
}

\begin{abstract}
Heavy slurry pumping is facing enormous problems concerning pressure generation and casing limitations. Pumping highdensity cement throughout narrow column, throttled at their extremity by the float equipment will generate more pressure, and could push casing to their limits of utilization. There are numbers of phenomena that could lead to casing length change as: piston, ballooning, temperature, tension and buckling. This work is oriented to study buckling effect on total casing length change. Generally, in conventional wells cementing, down hole conditions are referred to geological formation fracture pressure limit, which is lower than buckling limit. Heavy slurry displacement could make an exception, where buckling could appears at pressure inferior to geological fracture limit. While pumping heavy cement down, pressure inside casing increases progressively, pushing casing to extend, consequently risk of closing the narrow space out between casing and open hole total depth may appears. At this moment, buckling begins; pressure rise intensely to reach geological fracture limits and causes down hole loses. After passing the critical high pressure situation, casing will come back to their initial form. In order to overcome this situation, maximum allowable pressure during displacement together with problem indicators is proposed, to prevent and early detect the problem. Experimental and simulation results confirm the usability of assumption proposed.
\end{abstract}

Keywords Heavy cement job $\cdot$ Casing limitations $\cdot$ Maximum allowable surface pressure $\cdot$ Buckling indicators

\section{List of symbols}

$F_{\mathrm{b}} \quad$ Buckling force (fictitious force) (lbf)

$F_{\mathrm{a}}, T$ Tension force of casing string (lbf)

$F_{\text {ad }} \quad$ Additional buckling force caused by change in pressure from internal to external casing (lbf)

$F_{\mathrm{c}} \quad$ Critical buckling force, $\mathrm{lbf}$

$A_{\mathrm{i}} \quad$ Area of the casing internal diameter, $\left(\mathrm{in}^{2}\right)$

$A_{\mathrm{o}} \quad$ Area of the casing outer diameter, $\left(\mathrm{in}^{2}\right)$

$B_{\text {Bof }} \quad$ Buoyancy force (lbf)

$B_{\mathrm{f}} \quad$ Buckling force engender by buoyancy force (lbf)

$E \quad$ Elongation due to tensile load (in)

$\Delta E \quad$ Variation elongation due to change in tensile load (in)

$P_{\mathrm{i}} \quad$ Equivalent inside casing bottom pressure, (psi)

Po Equivalent annulus bottom pressure, (psi)

$N \quad$ Neutral point, in

$W \quad$ The buoyed weight per unit length, lbf/in

Ws Weight of steel per unit length, lbf/in

Wi Weight of fluid inside casing per unit length, lbf/in

Abdeslem Leksir

Leksir1@yahoo.fr

1 SONATRACH, University of ANNABA, Annaba, Algeria
Wo Weight of fluid outside casing per unit length, lbf/ in

$P_{\text {ihyd }} \quad$ Equivalent inside casing hydrostatic pressure, (psi)

$P_{\text {surf }} \quad$ Surface pressure, $(\mathrm{psi})$

$P_{\max } \quad$ Maximum allowable Surface pressure, (psi)

$P_{\Delta L} \quad$ Trapped pressure due to buckling effect

\section{Introduction}

Cementing job is one of the most critical operation executed during well life cycle, represents long production period or safe abandonment, this is according to how well cement job is done. The main objective is to achieve section goals safely, overcome down hole barriers, and start further drilling in order to reach the reservoir (Lavrov and Torsaeter 2016). Casing running and cementing are the tools that offer warranty to realize further operations safely, and preserve well integrity. Generally, casing design is oriented to confirm burst and collapse resistance first (Zhang et al. 2017).

Several papers have been deal with this subject in terms of cement quality innovation (De Andrade et al. 2016), cement materials (API SPEC 10A 2010), field way of application and equipment (Dooply et al. 2016), displacement and 
mud removal (Bittleston et al. 2002; Pelipenko and Frigaard 2004), software and program actualization with down hole conditions. This paper is oriented to study influences of density and pressure variations during cement job, on casing total length elongation due to buckling effect (Chesney and Garcia 1969; Hammerlindl 1980). It is well known that casing-hole depth space out is limited, thus any elongation exceed this interval will have severe impacts, on job smooth running and cement quality. String in hole could be affected by variety of forces that engender change of total casing length. Generally, variation either of temperature or pressure will have results on string length modification. The associated phenomena which should be taken into count are piston effect, ballooning effect, temperature effect and buckling effect.

Piston effect occurs when difference of pressure appears between inside and outside string (Lyons et al. 2016; Kenneth 1982). All variations in pressure are referred to packer, in case of production or formation restriction in case of drilling. Either while casing running or cementing operation, there is no obstacle behind casing, annulus is free witch make this phenomenon not applicable.

Ballooning or reverse ballooning effect, appears if inside pressure is much different from annulus pressure (Lyons et al. 2016; Kenneth 1982). Regarding to ballooning type, force generated will be an upward or downward. During cementing, especially while cement is pumped, inside pressure will be higher than annulus pressure. Ballooning occurs and reduction in total casing length takes place. Then the case of casing depth extension is fare from ballooning effect.

Different from other phenomena, change in column length due to temperature is not affected by pressure variation (Lyons et al. 2016; Kenneth 1982). While running casing, temperature change in length will be introduced progressively until reaching the bottom (temperature gradient). Consequently, no modification in casing length due to temperature variation occurs during cement job.

Buckling or helical buckling effect appears if two phenomena were verified. Differential pressure between inside and outside string is registered, and neutral point located inside casing depth (Chen and Cheatham 1990; Lyons et al. 2016). Then, when bottom is not tagged, buckling doesn't exist which is the case before casing cement job. While running cement job, buckling problem may occur, even if U-tube effect is verified, surface pressure could make the difference.

During drilling and completion operations, buckling should be avoided to preserve tubular from wear. Different studies have been carried out in the literature to clarify buckling effects (Mitchell 1982).

Mitchell (1999) and Chen et al. (1990) present a practical method to analysis buckling effect in deviated wells, referred to Paslay force compared to buckling force, buckling existence will be judged accordingly. This assumption is actualized and generalized by the same author Mitchel (2008). More oriented method presented by (Mitchell 1982), to analysis buckling effect in completion wells. Wang (1986) proposes an analytical model of long hanging column with a bottom subject to compressive force or free to move. Wu and Juvkam-Wold (1995), predicts helical buckling occurrence through analysis of energy generation.

Klinkenberg (1951) proves influence of fluid characteristics, especially pressure, on neutral point position. This later study was oriented toward buckling analysis by (Lubinski et al. 1962), based on "Fictitious" force analysis. Later Chesney and Garcia (1969) and Hammerlindl (1980) generalize the theory of fluid influences on string buckling force to cover different pressure and density, from internal to external tubular side.

This paper is oriented to study buckling force generated while cementing and displacement of heavy slurry. Limitations faced pumping heavy slurry includes significant density and consequently high pressure generated at surface. Method presented in this paper, permit prediction of maximum allowable surface pressure and run heavy cement job safely. First, analytical and simulation study is carried out to point out the effect of casing buckling on cement job smooth running. Finally, cases study and offset wells are detailed to confirm the usability of assumption.

\section{Casing buckling problem description and analysis}

Cement job is a critical operation in terms of pressure and density variation. In conventional job, cement density is much higher than mud density. Consequently, when slurry is pumped inside casing, equivalent height of mud will be flow out from the annulus (Lavrov and Torsaeter 2016). Displacement continues in "free fall" state, till reaching the first bump, when slurry pushed to open hole (Wellington et al. 1993). While cement moves in open hole, hydrostatic pressure increases progressively. Surface pressure rise in order to overcome backup pressure generated, which keep fluids moving. Generally, when cement is pumped inside column, equilibrium is created in terms of equivalent pressure between inside and outside casing. In the case of cement moved in annulus, surface pressure rise to fight the new equivalent hydrostatic pressure and keep fluids moving.

While pumping heavy slurry, even if the gap in pressure between fluids is limited, immense pressures are generated and may break buckling limits.

A case study has been taken into count to pinpoint toward heavy slurry cementing job borders. Well drilled in south Algeria to $3620 \mathrm{~m}, 9 " 5 / 8$ (3200 m of 53.5\#, $420 \mathrm{~m}$ of $47 \#$ ) casing run and cement pumped without remarkable problem. 
While displacement pressure rise to $2350 \mathrm{psi}$, and remain stable even if pumping is still ongoing. This later, before finishing pumping first bump volume $(6.62 \mathrm{~m} 3$ missed). Situation is judged critical and a decision has been taken to stop cementing process, all cement left in hole. Sidetrack takes place, drilling to almost the same depth (3616 m), and 9"5/8 casing ( $2542 \mathrm{~m}$ of $53.5 \#, 1073 \mathrm{~m}$ of $47 \#$ ) was run. Practically the same problem persists and cement cannot be pushed in the annulus smoothly ( $36 \mathrm{~m} 3$ losses). Remedial cement job has been done through perforations successfully. Table 1 summarizes well characteristics:

In first job, hook load doesn't appear in mud logging chart, only rise of pressure is registered. It can be clearly seen, in Fig. 1b-that several attempts have been done to continue cement job without success. Pressure rises to 2350 psi and remains stable, even if pumping is still ongoing, which indicate that geological barrier is reached (formation fracture pressure limit).

Second cement job has been done after three months as shown in Fig. 1c, and the same scenario repeats. Pressure rise to 2700 psi maximum, with almost same results. In addition to pressure chart, hook load was registered too (Fig. 2).
Even that all weight supposed to be hanged and casing was off bottom, chart (Fig. 2) clearly mentioned a slight decrease in hook load parallel to pressure rise. This makes the situation doubt and pushes assumption of down hole fracturing fare from the reality.

\section{Casing buckling effect}

Deeper analyses in casing design are oriented to study buckling in horizontal wells (Chen et al. 1990), and in completion string (Lubinski et al. 1962). Clark (1987) suggests that buckling force is negligent and should not be considered in most cases. This is not the case in heavy slurry pumping, where variation in pressures are narrow as setting depth is deeper, and free fall will not be practically registered. Casing Buckling force is given by Lubinski et al. (1962) as follow:

$F_{\mathrm{b}}=F_{\mathrm{a}}+F_{\text {ad }}$

$F_{\mathrm{b}}$ is the buckling force (fictitious force) (lbf), $F_{\mathrm{a}}$ is the casing tension or compression force (lbf), $F_{\text {ad }}$ is the additional buckling force caused by change in pressure from internal
Table 1 Cement job and casing characteristics

\begin{tabular}{|c|c|c|c|c|c|}
\hline Cement job & Casing & $\mathrm{TD}(\mathrm{m})$ & Casing TD (m) & Cement & $\begin{array}{l}\text { Displacement } \\
\text { (m3) program/real } \\
\text { pumped }\end{array}$ \\
\hline First job & $9 " 5 / 8(53.5 \#, 47 \#)$ & 3620 & 3619 & $\begin{array}{l}10 \mathrm{~m} 3 \text { of spacer } \\
(2.29 \mathrm{sg}), 43.44 \\
\mathrm{~m} 3 \text { of slurry } \\
(2.31 \mathrm{sg})\end{array}$ & $13,271 / 81$ \\
\hline Second job & $9 " 5 / 8(53.5 \#, 47 \#)$ & 3616 & 3615 & $\begin{array}{l}7 \mathrm{~m} 3 \text { of spacer } \\
(2.3 \mathrm{sg}), 45.41 \\
\mathrm{~m} 3 \text { slurry } \\
(2.32 \mathrm{sg})\end{array}$ & $133 / 98$ \\
\hline
\end{tabular}

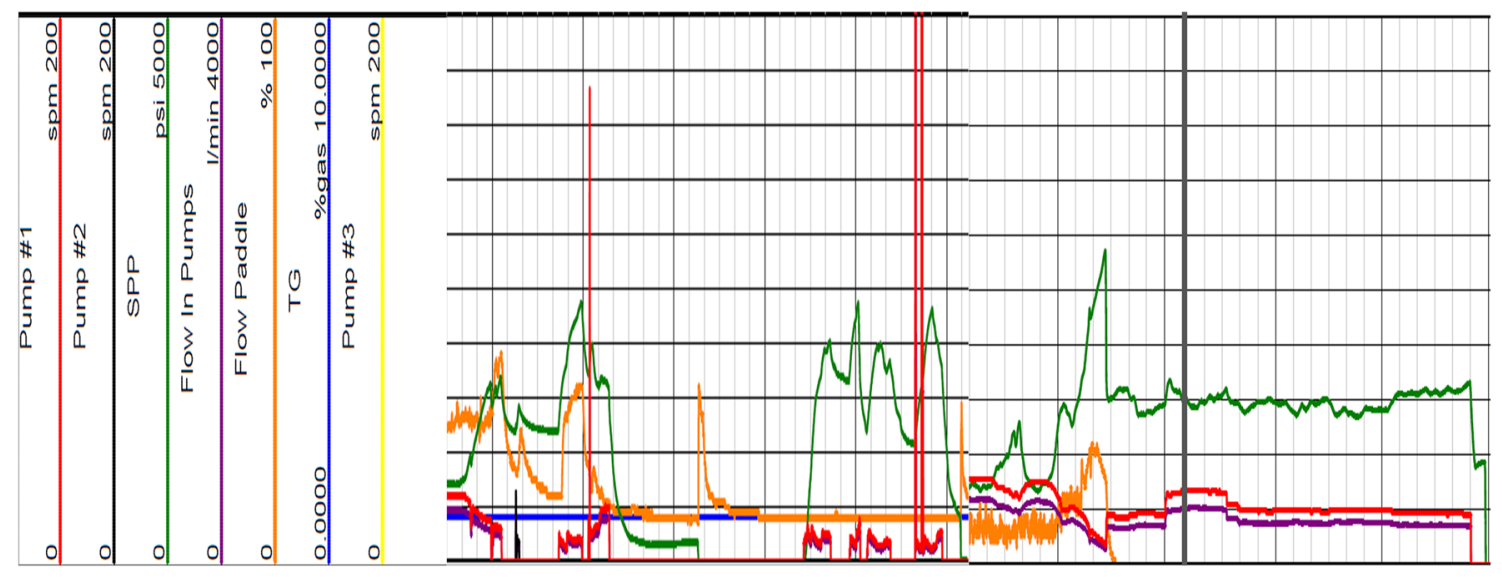

(A) Scale
(B) First Cement Job
(C) Second Cement Job

Fig. 1 9" 5/8 displacement chart for the first cement job B and the second C 
Fig. 2 9" 5/8 displacement chart for the second job with hook weight variations

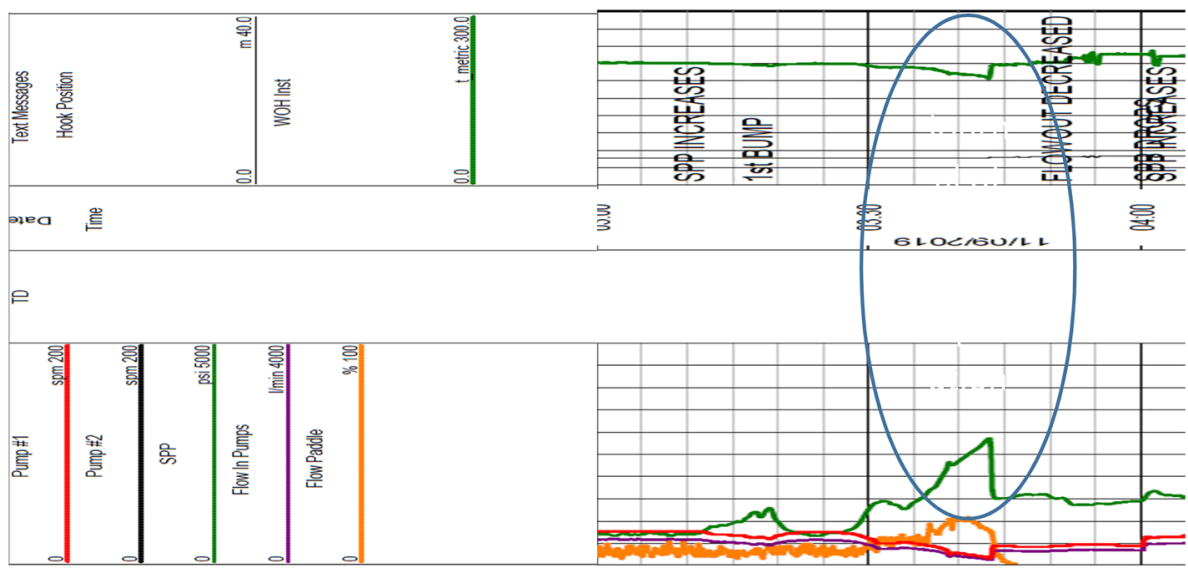

to external casing (lbf), buckling force $\left(F_{\mathrm{b}}\right)$ is the sum of unvarying force $\left(F_{\mathrm{a}}\right)$ generated by casing weight, and an additional variable force $\left(F_{\text {ad }}\right)$ according to down hole conditions.

$F_{\text {ad }}$ is given in (Lubinski et al. 1962) by the expression below:

$F_{\text {ad }}=A_{\mathrm{i}} P_{\mathrm{i}}-A_{\mathrm{o}} P_{\mathrm{o}}$

$A_{\mathrm{i}}$ is the area of the casing internal diameter. $\left(\mathrm{in}^{2}\right), A_{\mathrm{o}}$ is the area of the casing outer diameter. $\left(\mathrm{in}^{2}\right), P_{\mathrm{i}}$ is the equivalent inside casing bottom pressure, (psi), $P_{\mathrm{o}}$ is the equivalent annulus bottom pressure, (psi).

Buckling will occur if inside pressure generated $A_{\mathrm{i}} P_{\mathrm{i}}$ is greater than outside pressure $A_{\mathrm{o}} P_{\mathrm{o}}$. In order to clearly describe the buckling apparition level, the notion of neutral point should be introduced. Neutral point $(N)$ indicates the limit where string convert form tension to compression state. If neutral point is greater than string length $(N>L)$, string is in tension state. If neutral point is less than length of the string $(N<L)$, string is in tension from the top to the neutral point, and from neutral point to total length $\mathbf{L}$ string is in compression state. At neutral point, string is in equilibrium state, this means neither compression nor tension will be recorded.

Taking into count that casing is off bottom, length change due to casing additional tensile may push column to tag bottom. Then compression begins and their effect is given by neutral point in Lubinski et al. (1962) as follow:

$N=\frac{F_{\mathrm{b}}}{W}$

$N$ is the neutral point (in), $W$ is the buoyed weight per unit length (lbf/in), $W$ is defined by Lubinski et al. (1962) as:

$W=W_{\mathrm{s}}+W_{\mathrm{i}}-W_{\mathrm{o}}$
$W_{\mathrm{s}}$ is the weight of steel per unit length (lbf/in), $W_{\mathrm{i}}$ is the weight of fluid inside casing per unit length (lbf/in), $W_{\mathrm{o}}$ is the weight of fluid outside casing per unit length (lbf/in).

Buckling appears only if the neutral point length $\mathrm{N}$ is less than the casing setting depth $\mathrm{L}$. introducing this assumption Eq. 3 will be:

$\frac{F_{\mathrm{b}}}{W}<L$

Casing cementing operation is characterized by open annulus (no pressure in surface outside casing), and inside surface pressure related to pumping rate. The equivalent pressure inside casing will be given by:

$P_{\mathrm{i}}=P_{\text {isurf }}+P_{\text {ihyd }}$

The equilibrium state defined in Eqs. $(2,4,5)$ is introduced, in order to distinguishing the surface controllable pressure from down hole unvarying equivalent hydrostatic pressure.

$\frac{F_{\mathrm{a}}+A_{\mathrm{i}}\left(P_{\text {surf }}+P_{\text {ihyd }}\right)-A_{\mathrm{o}} P_{\mathrm{o}}}{W}=L$

The maximum allowable pressure at surface, before the beginning of buckling is given by:

$P_{\max }=\frac{F_{\mathrm{a}}-w L-\left(A_{\mathrm{i}} P_{\text {ihyd }}-A_{\mathrm{o}} P_{\mathrm{o}}\right)}{A_{\mathrm{i}}}$

If surface pressure is inferior than maximum allowable pressure, $P_{\text {surf }}<P_{\max }$. Then the casing is in tension state and consequently there is no change on the total length. If surface pressure is equal to maximum allowable pressure, $P_{\text {surf }}=P_{\text {max }}$, then casing string is in critical state, there is neither compression nor tension. If surface pressure is greater than maximum allowable pressure, $P_{\text {surf }}>P_{\max }$, then part of casing string will receive a compression force, buckling occurs and consequently casing length will change. 
Space out between casing setting depth and total open hole will be reduced, thus surface pressure will rise accordingly.

Cement job is run in three stages, cement pumping, displace inside casing and push in open hole in order to seal geological formations (Bittleston et al. 2002). Differently, while displacing cement inside casing, if slurry density is close to mud (around or more than $1.9 \mathrm{sg}$ cement, in conventional cement), inside hydrostatic column is greater than the outside column. To achieve good mud removal a high flow rate will be applied and engender high stand pipe pressure (Bittleston et al. 2002), which enhance downward forces and may generate casing buckling.

When string is immerged in fluid an upward force created named buoyancy force, and acting as a compressive force (Kaarstad and Aadnoy 2011).

Buoyancy force, in homogeneous fluid, is given by equation Eq. 8 (Arnfinn and Naval 2017):

$B_{\text {Bof }}=\left(A_{\mathrm{o}}-A_{\mathrm{i}}\right) P_{\mathrm{h}}$

Buckling force can be obtained by adding the weight of string $F_{\mathrm{a}}$ (Arnfinn and Naval 2017):

$B_{\mathrm{f}}=F_{\mathrm{a}}+\left(A_{\mathrm{i}}-A_{\mathrm{o}}\right) P_{\mathrm{h}}$

In case of different density from inside to outside, Eq. 8 will be written as follow (Kenneth 1982):

$B_{\mathrm{Bof}}=A_{\mathrm{o}} P_{\mathrm{ho}}-A_{\mathrm{i}} P_{\mathrm{hi}}$

Similarly, buckling force will be written as (Kenneth 1982):

$B_{\mathrm{f}}=F_{\mathrm{a}}+\left(A_{\mathrm{i}} P_{\mathrm{hi}}-A_{\mathrm{o}} P_{\mathrm{ho}}\right)$

Buckling is one of the most complicated effects in terms of appearance conditions and acting phenomena. During cement operation, casing is hanged from the top and free to move at the bottom. Consequently, in normal conditions, there is no mechanical force acting on casing end in upward direction. While displacing cement, difference between inside equivalent pressure $\left(A_{\mathrm{i}} P_{\mathrm{i}}\right)$ and outside pressure $\left(A_{\mathrm{o}} P_{\mathrm{o}}\right)$, gives an overview of the buckling situation (Lyons et al. 2016). If the new inside equivalent pressure is much greater than the original one, a downward force generated and buckling may take place. Different from other effect, buckling is related to neutral point (Klinkenberg 1951), which represents the passage from tension to compression.

Generally, suspended casing is exposed to tension force produced by their own weight, unless interaction of other drilling parameters. Fluid density and flow rate variations will influence the total weight suspended, increasing/ decreasing density and/or flow rate, will be projected on lifting capability of the hole system (Mitchell 1999). Consequently, column will be exposed to either shortage or elongation, based on tensile or neutral point position from the total depth.

Elongation due to tension load is given by (API RP 7G 1998):

$E=(L * T) /(735294 * W)$

$E$ is the elongation due to tension load (in), $T$ is the tension load (lbf).

As it is clearly seen in Eq. 12, any variation in string weight will projected on elongation or shortage. Buoyancy force reduces the total weight of column, during pumping cement inside casing lifting force decrease Eq. 4. Suspended column recover part of their weight proportional to lifting force reduced. Therefore, elongation will be greater according to column length and weight recovered (Jellison and Brock 2000).

In order to avoid confusion between buckling and piston effect occurred when inside casing is plugged by flash setting. Figure 3 presents the elongation of column caused by piston effect at the top plug. Elongation due to piston effect reaches stage of closing flow itinerary, when pressure is more than 3500 psi at surface. This later is described by
Fig. 3 Elongation of casing due to piston effect at top plug in case of flash setting

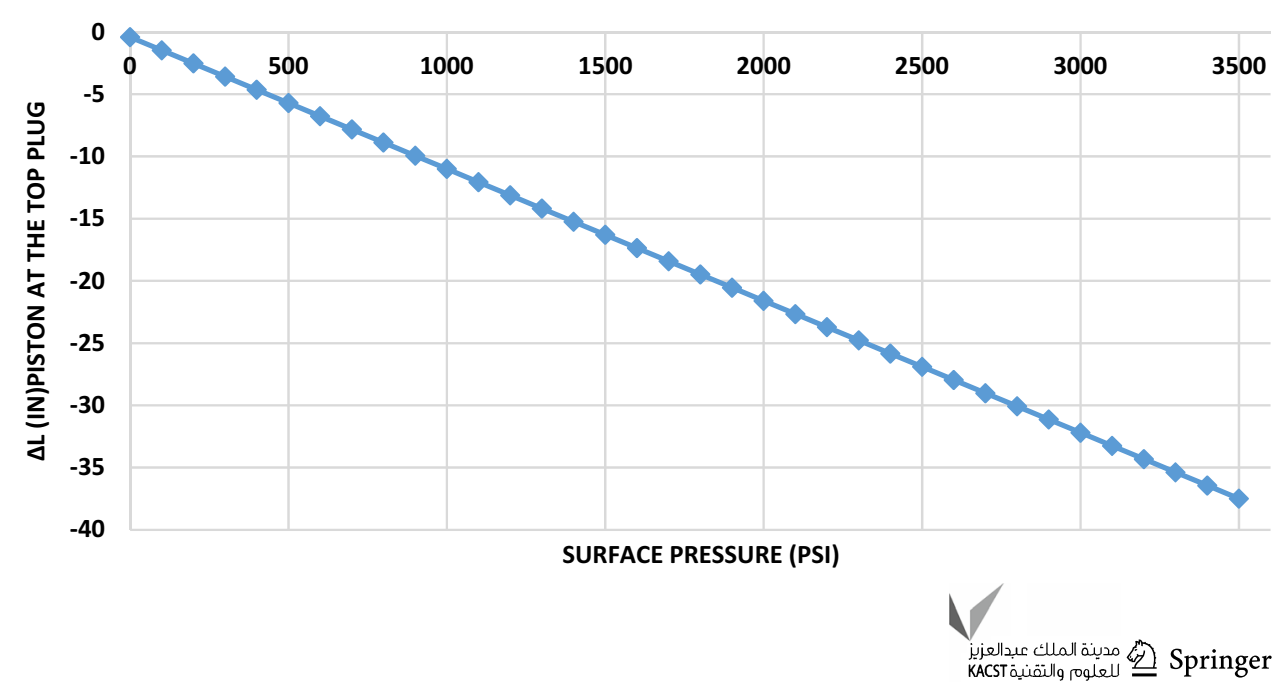


one meter of casing elongation (overlap between casing and total section depth), to tag bottom. This makes assumption of piston effect far from the reality, and cannot be taken into count.

Long sections is becoming more likely when drilling nonconventional wells, as slime hole or ERD (extended reach drilling) (Stair and Mcinturff 1986). This later will have challenge in terms of all drilling operations include casing running and cement (Ahmed et al. 2019). Generally, to overcome down hole limitations two casing grad is used, lower grad in upper side and high grad in lower side. This procedure work very well with conventional drilling, but presents a high risk of buckling with long section. Lower grad casing selected for top section will have less cross-sectional area and consequently low resistance to elongation. Moreover, high grad used in bottom part will generate more weight, which makes the situation worst.

Generally, when cement pumped down hole to reach their goal in annulus, buoyancy force vary from inside to outside as it is presented in Fig. 4. At the beginning casing is submerged in homogenous mud, applying Eq. (8) buoyed force is $158,000 \mathrm{psi}$. As cement is pumped, hydrostatic pressure inside becoming greater than hydrostatic outside, consequently value of Eq. (10) reduced continuously to reach their minimum $(152,678 \mathrm{psi})$. When cement start come out in the annulus, outside hydrostatic pressure rise progressively to reach their maximum at the end of displacement $(166,653 \mathrm{psi})$. Inversely, the total casing weight hanged Eqs. (9) and (11) follow the opposite way. When cement pumped inside, some casing weight recuperated increasingly to reach their maximum when all cement is pumped inside. As cement begin take place in annulus, outside hydrostatic pressure rise, which make outside behavior of Eq. (10) bigger and reduction in weight in Eq. (11) smaller. Hydrostatic pressure reach their minimum when cement cover all geological open hole and overlap, remained height inside casing represents spacer, which is pumped before plug. Finally, the critical zone is when cement pumped inside casing and just before first bump.

In order to understanding the phenomenon of buckling, we orientate the extraction of indicators toward casing column weight variations. During cement job, pumping cement downward in casing will increase inside fluid density and surface pressure. Equilibrium between tension force engendered by casing weight, and compression force generated by buoyancy force will be disturbed. First indicator is the presence of free fall; this later will preserve the equilibrium in terms of inside and outside equivalent hydrostatic pressure. During cementing heavy slurry, depleted reservoir and more generally when cement density is close to drilling fluid density, hydrostatic equilibrium between inside and outside casing will be lost. Consequently, part of casing weight suspended by buoyancy effect Eq. (8), will be reduced Eq. (10) which maximize tensile and reduce buoyancy effect. Accordingly, more tensile engender additional casing elongation, tagging total depth and close the flow itinerary may occurs. This later will leads to stop cement job, stand pipe pressure rise dramatically to reach plugging stage, and cement will be left inside casing. Thus, indicators are the absence of free fall, elongation due to tensile greater than the casing space out.

Introducing Eqs. (9) and (11) in the elongation Eq. (12) we will have:

In case of homogeneous mud:

$E=\left(F a-\left(A_{\mathrm{o}}-A_{\mathrm{i}}\right) P_{\mathrm{h}}\right) *(L) /(735294 * W)$

In case of different density from inside to outside

$E=\left(F a-\left(A_{\mathrm{o}} P_{\mathrm{o}}-A_{\mathrm{i}} P_{\mathrm{i}}\right)\right) *(L) /(735294 * W)$

Subtracting Eq. (14) from Eq. (13) in order to get the net variation of elongation which will be given by:
Fig. 4 Variations of Buoyancy force during cement displacement

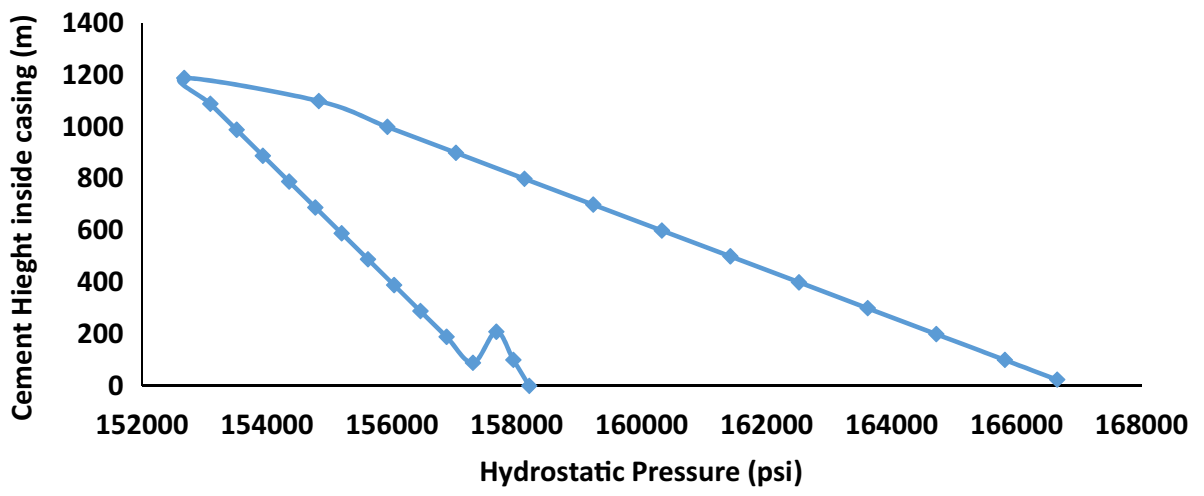

$\multimap(\mathrm{Ao}) \mathrm{Po}-(\mathrm{Ai}) \mathrm{Pi}$ 
$\Delta E=\left(\frac{\pi * 0.052}{735294}\right) *\left(\frac{r^{2} L^{2}}{W}\right) *\left(\rho_{\mathrm{i}}-\rho_{\mathrm{o}}\right)$

$\rho_{\mathrm{i}}$ is the inside casing fluid equivalent density (cement inside casing), $\rho_{\mathrm{o}}$ is the outside casing mud density.

Based on casing characteristics, pumping sequences and casing space-out length from the bottom, we can select a casing grade using Eq. (15), which will support internal equivalent density variations. It can be clearly seen in Eq. (15), selecting upper grad will minimize inside diameter and maximize buoyed weight by unit length. Consequently, upper casing grad will minimize elongation effect caused by additional tensile as shown in Fig. 5.

The minimum casing load that causes buckling in vertical wells is characterized by the critical buckling force given in equation Eq. (16) (Marbun et al. 2014):

$F_{\mathrm{c}}=550\left[\frac{I * W_{\text {String }} *\left(65.6-M_{\mathrm{w}}\right)}{\left(D_{\mathrm{h}}-D_{\mathrm{Tj}}\right)}\right]^{\frac{1}{2}}$

$F_{\mathrm{c}}$ is the critical buckling force, lbf, $I$ is the casing moment of inertia, in ${ }^{2}, W_{\text {String }}$ is the weight of casing string in air, lb/ $\mathrm{ft}, M_{\mathrm{w}}$ is the mud density, ppg, $D_{\mathrm{h}}$ is the hole diameter, in, $D_{\mathrm{Tj}}$ is the tool joint diameter, in.

In order to quantify the gravity of casing situation, a maximum allowable surface pressure is proposed. Maximum elongation of casing string before buckling is achieved, when space out between casing and open hole is closed ( $\Delta E=$ space out between casing and open hole).

Maximum allowable surface pressure is given by relation below:
$P_{\max }=\left(\frac{735294 * W}{A_{\mathrm{i}} L}\right) * \Delta E-\Delta P_{\mathrm{h}}$

$\Delta P_{\mathrm{h}}=P_{\mathrm{ho}}-P_{\mathrm{hi}}$

Analyzing Eq. (17), shows the main specifications should be taken into count are:

- Casing characteristics.

- Section depth.

- Variation of equivalent hydrostatic pressure from inside casing to outside.

\section{Problem analysis}

In case of well mentioned in section "Casing buckling problem description and analysis", reaction of total weight on hook conjointly with rise of pressure, makes buckling assumption highly probable. Figure 6 presents variation of total buckling force $F_{\text {ad }}$, caused by change in surface pressure.

To point out casing characteristics influences on cement displacement, Figs. 6 and 7 contain buckling force variations for different 9"5/8 down hole conditions. The bleu squared line $\left(F_{\mathrm{a}}(\mathrm{Air})\right)$ represents real casing axial tensile force. When casing string is in fluid axial force acting is $\left(F_{\mathrm{b}}(\mathrm{mud})\right)$. Other axial forces appear in Figs. 6 and 7 represent influences of pressure variation on total force. Real, immersed and even when all cement is inside casing, total weight remain practically unchangeable. However, rise of inside surface pressure from 500 to 3000 psi push string to recover almost all their original weight $\left(F_{\mathrm{b}}\left(P_{\mathrm{s}}=3000\right)\right)$.

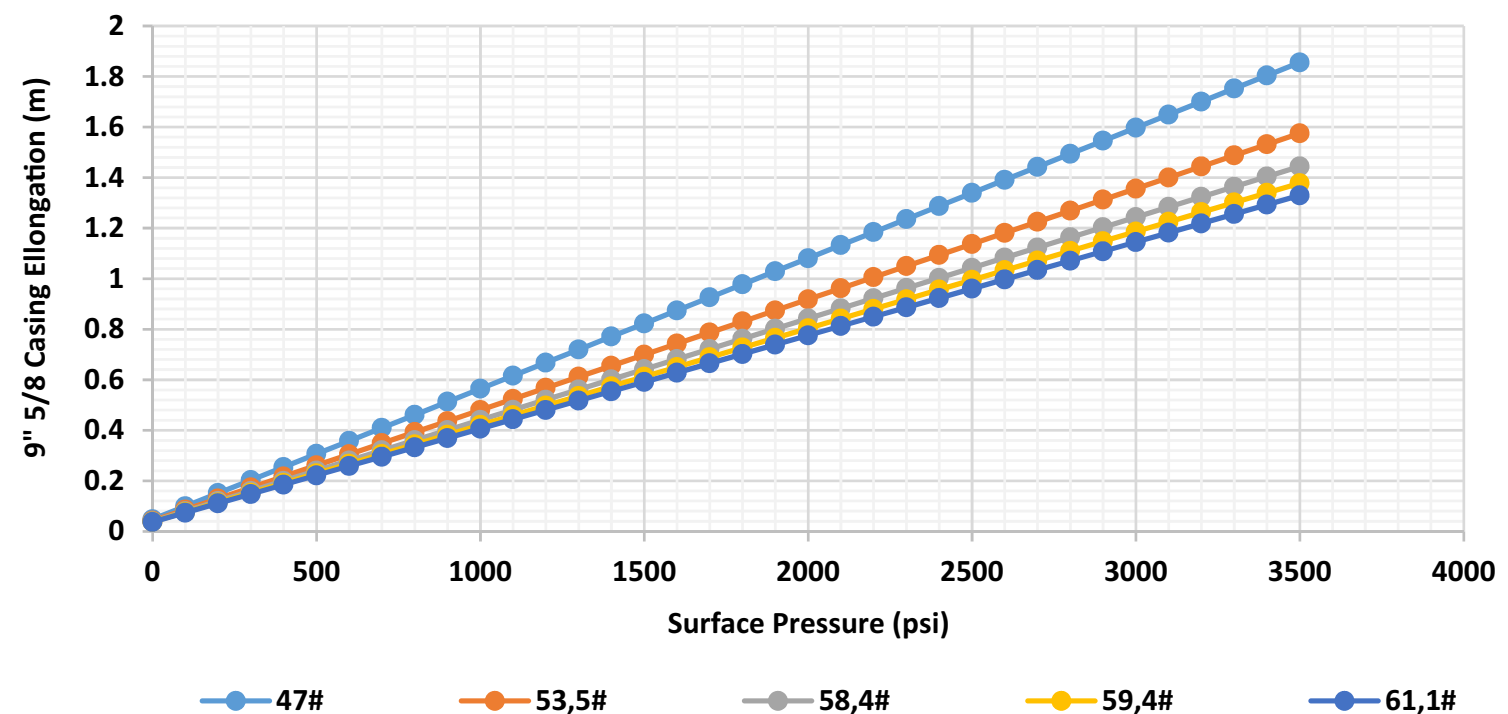

Fig. 5 Different casing grade elongation due to additional tensile effect 


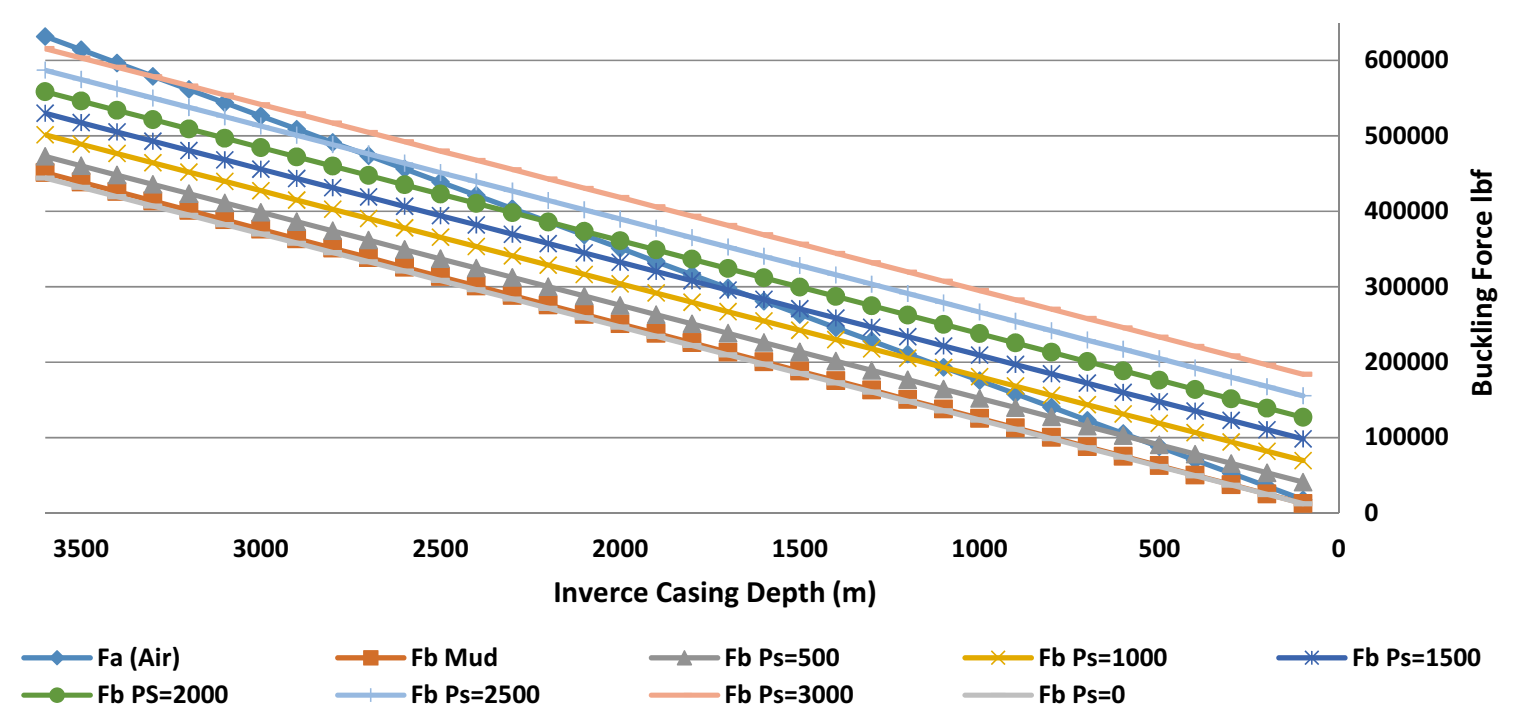

Fig. 6 Variation of additional buckling force compared to casing depth (9" 5/8 (53.5\#) casing)

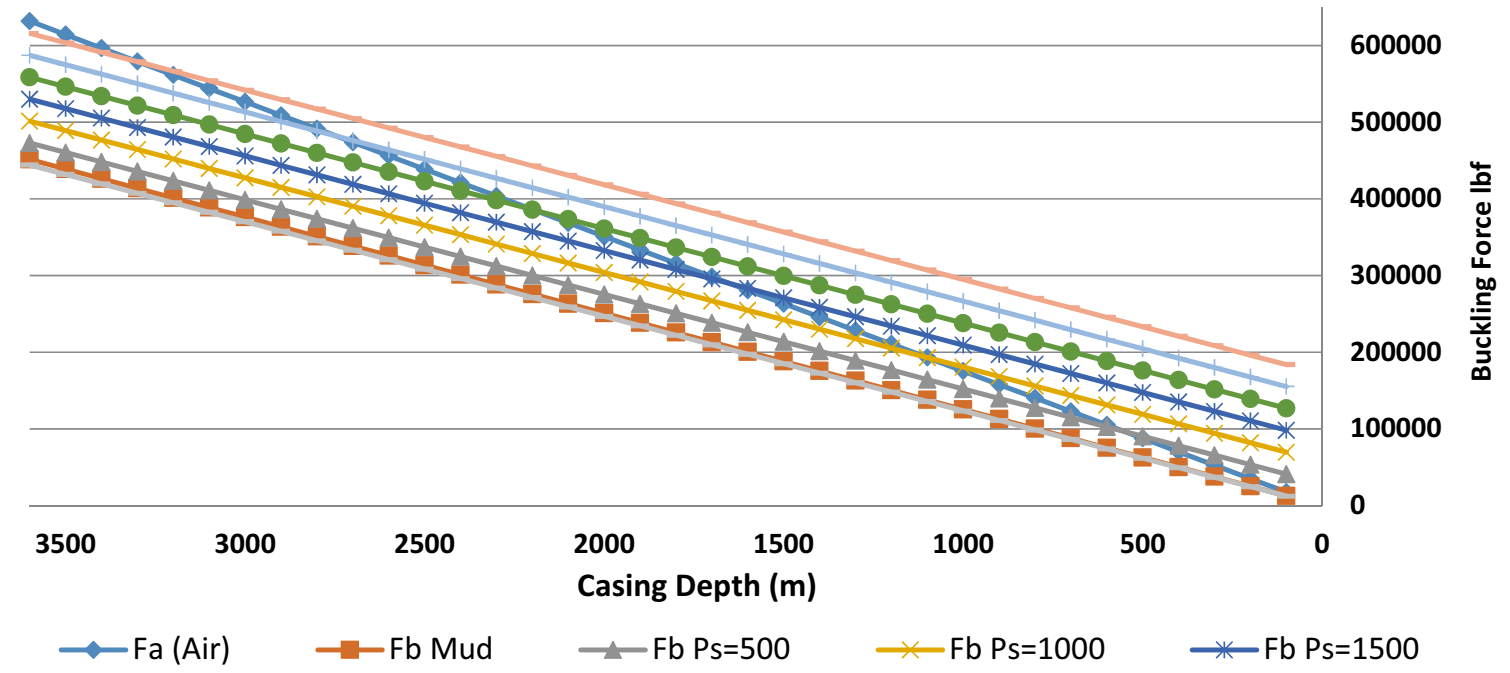

Fig. 7 Variation of additional buckling force compared to casing depth (9" 5/8 (61.1\#) casing)

Table 2 Maximum allowable surface pressure for $9 " 5 / 8$ cement job

\begin{tabular}{llllll}
\hline 9"5/8 Casing (\#) & 47 & 53.5 & 58.4 & 59.4 & 61.1 \\
\hline MAX pressure (psi) & 2030.4 & 2380.1 & 2592 & 2712.72 & 2808.84
\end{tabular}

Analyzing results presented in Figs. 6 and 7, a limit of surface pressure before total closing of flowing itinerary and beginning of buckling could be attained. Maximum allowable surface pressure presented in Table 2, casing string is exposed to tension force only, and no buckling is recorded (elongation equal to casing-total depth overlap).

In order to overcome above limitations, simulation via the same fluid characteristics using 7" casing cement is proposed in Fig. 8.
Similar to 9" 5/8 casing, surface pressure push immersed 7" casing weight, as presented in Fig. 8, to almost the real weight $\left(F_{\mathrm{b}}\left(P_{\mathrm{s}}=3000 \mathrm{psi}\right)\right)$.

The maximum allowable surface pressure, before the beginning of buckling is presented in Table 3. All pressures exceed 3000 psi, which make this theory verified for all casing weight studied.

This study is generalized to cover larger casing diameters, 13 " $3 / 8$ casing is selected and the results are presented in Fig. 9.

Figure 9 presents total axial force variations compared to surface pressure. Even that axial force remain almost stable for all casings, 13"3/8 casing is the weakest one in term of tensile resistance. This later is confirmed in Table 4 , where maximum surface pressure during displacement of heavy 


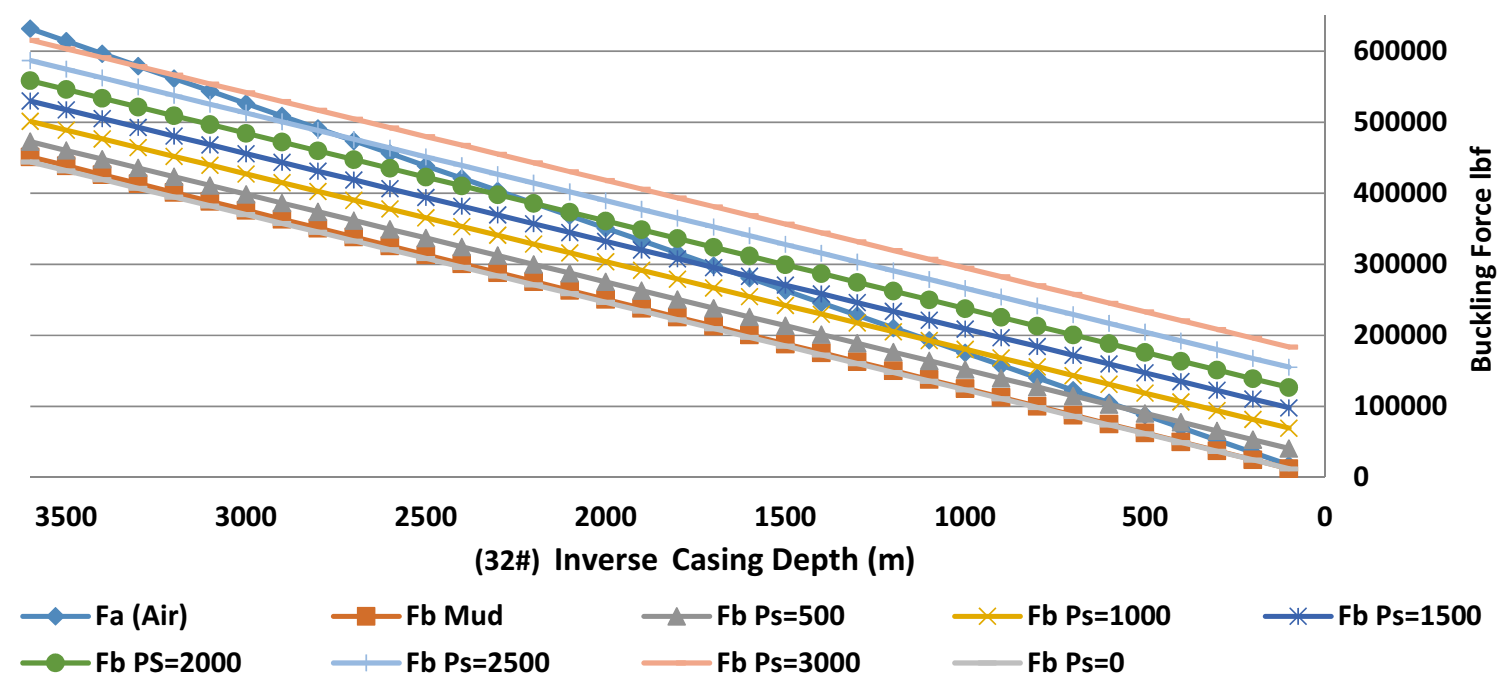

Fig. 8 Variation of additional buckling force compared to casing depth (7" (32\#) casing)

Table 3 Maximum allowable surface pressure for 7" cement job

\begin{tabular}{lllll}
\hline 7" Casing (\#) & 38 & 41 & 44 & 46 \\
\hline MAX Pressure (psi) & 3570.65 & 3969.92 & 4395.05 & 4682.94 \\
\hline
\end{tabular}

cement 13 " 3/8 casing doesn't exceed 2000 psi. Consequently, if the theory of maximum allowable pressure confirms the non-adequate of casing selected, just designate upper casing grade or even change the architecture of the well.

Table 4 Maximum allowable surface pressure for 13" 3/8 cement job

\begin{tabular}{lllll}
\hline 13 " 3/8 Casing (\#) & 68 & 72 & 77 & 80.7 \\
\hline MAX Pressure (psi) & 1417.24 & 1514.49 & 1635.52 & 1731.98 \\
\hline
\end{tabular}

Maximum allowable surface pressure theory could be useless, if it is superior to geological fracture pressure limit, or if their occurrence is fare from the real conditions.

If rises of pressure due to buckling occurs, while displacement or even during pumping heavy slurry. It is highly recommended to bleed off pressure and restart operations using minimum flow rate.

The overall meaning of maximum allowable surface pressure is the limit of casing elongation $(\Delta E)$ without tagging bottom. Beyond this border, no elongation $(\Delta E)$ could be attained. Consequently, compressive force will be generated.

Results presented in Fig. 10 could be surmised as follows:

- In air only tension appears, the neutral point located at the bottom of string.

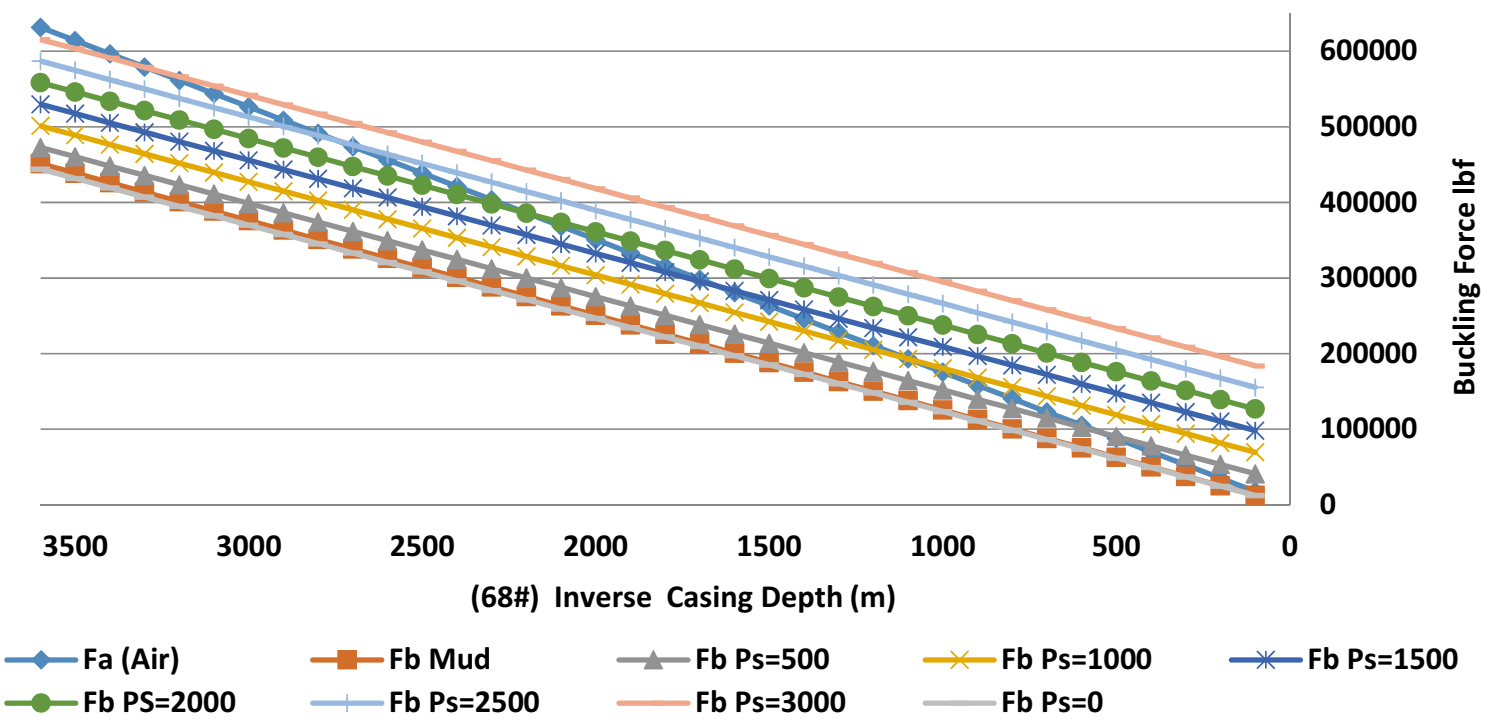

Fig. 9 Variation of additional buckling force compared to casing depth (13"3/8 (68\#) casing) 
Fig. 10 Neutral pint and buckling force variation under different down hole conditions. (Hammerlindl 1980)

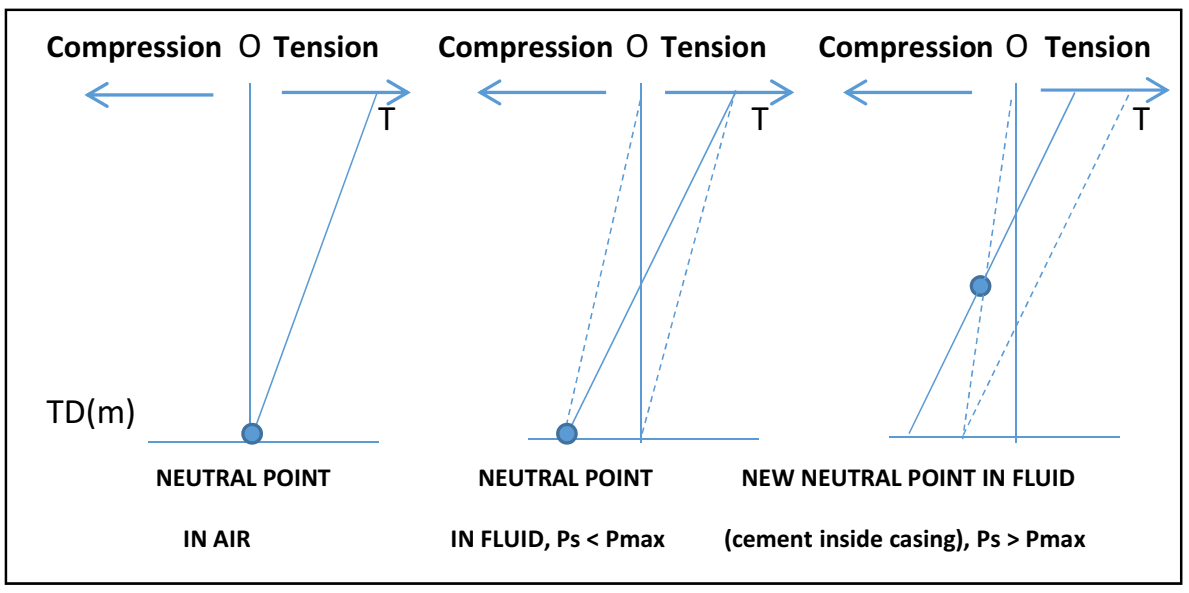

- When string is submerged in fluid and surface pressure under Pmax, neutral point still located at the real bottom. However, some of weight will be supported by buoyancy force.

- When cement is pumped inside casing and start displacement, if surface pressure is greater than Pmax (Elongation of string reach TD), neutral point will move upward inside casing. Consequently, compression force is generated and buckling take place. More details of casing buckling could be found in Hammerlindl (1980).

\section{Buckling indicators and offset wells interpretation}

It is practically difficult to follow buckling effect influences in the past wells, this later due to lack of accurate information which makes the situation doubt (Leksir 2020). However, based on interaction between characteristics, in some specifications of flash setting and buckling; we can compare total section depth to maximum elongation $\left(P_{\max }\right)$. If maximum elongation is greater than total depth, then buckling may take place. Appendix A comprises ameliorative actions, which could be used to overcome the problem safely. Appendix B offerings a number of sections cemented and pressure rise before ending the required displacement volume, reduction in casing weight will be pointed out too. Slurries and buckling characteristics are detailed in Appendix $\mathrm{C}$ and Appendix D, respectively. Appendix E contains a comparison between surface pressure presented in cement program, real job and the occurrence of buckling.

Similar scenario occurs in similar wells, pressure rise rapidly together with a decrease in column weight, as it is clearly presented in Fig. 11. Displacement at more than $10001 \mathrm{pm}$ flow rate take place for a round $80 \mathrm{~min}$, which equivalent to around $80 \mathrm{~m} 3$ of cement out of $122 \mathrm{~m} 3$ programed, attempts to complete the remained volume are achieved, only $10 \mathrm{~m}$ height of cement left in hole. Pressure rise from 380 psi to reach 3400 psi, and correspondingly casing column weight decrease form 214 ton to 170 ton.

To confirm the occurrence of buckling effect, casing weight should be recovered, at the time of pressure bleed off, as it is mentioned in Fig. 12.
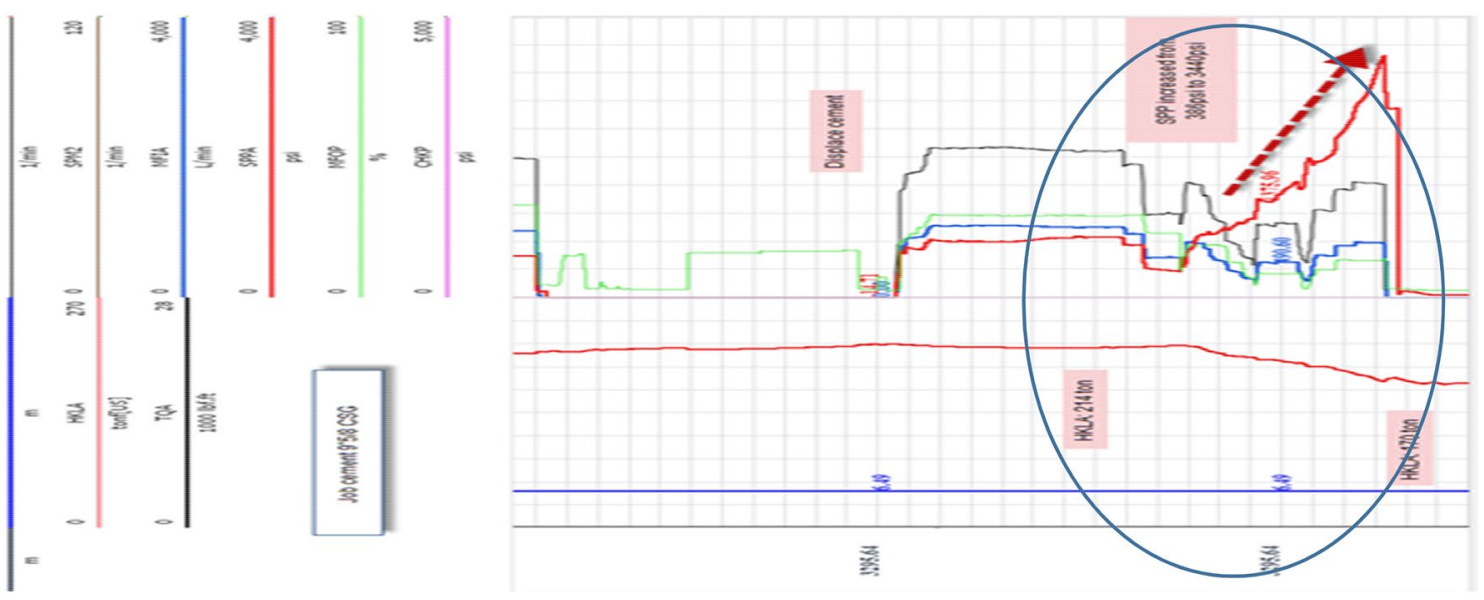

Fig. 11 9" 5/8 casing cement job chart 
Buckling effect problem sequences are detailed as follow:

- First, casing is in safe position (Tension) and neutral point situated out of total depth, without circulation.

$P_{\mathrm{i}}=P_{\text {hy }}$

- Second, casing is in safe position (Tension), with normal flow rate (Pmax not reached).

$P_{\mathrm{i}}=P_{\text {hy }}+P_{\text {surf }}$

- Third, rise of flow rate will push elongation of casing to reach total depth. Consequently, narrow gap between casing and total depth will be shorter and pressure rise excessively. If pressure continues increasing part of casing will exposed to compression.

$P_{\mathrm{i}}=P_{\mathrm{hy}}+P_{\Delta L}+P_{\text {surf }}$

At this moment, pressure applied on top plug will not convert to displacement, as consequence piston effect is generated.

- Fourth, when pumping stopped, apparent surface pressure comes down $P_{\text {surf }}=0$.

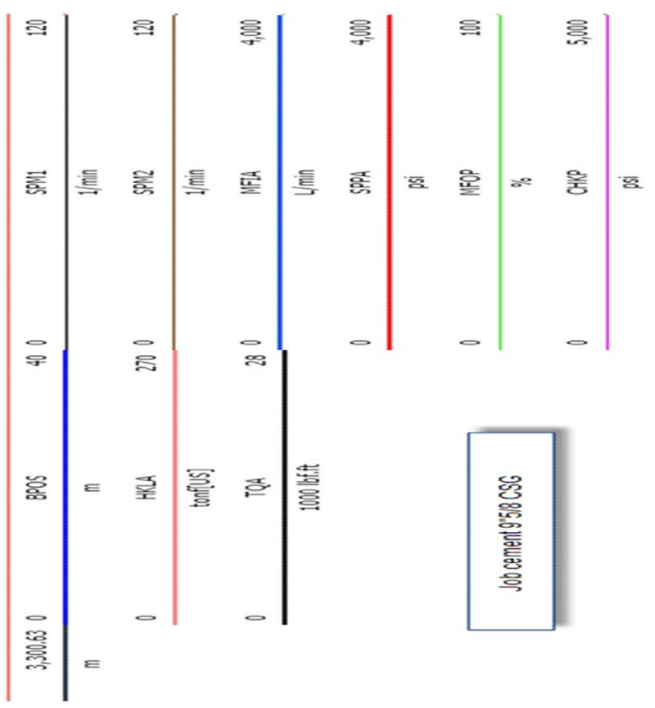

$$
P_{\mathrm{i}}=P_{\text {hy }}+P_{\Delta L}
$$

- Fifth, trapped pressure caused elongation will not be removed till the total bleed-off of pressure $\left(P_{\Delta L}=0\right)$.

$$
P_{\mathrm{i}}=P_{\text {hy }}
$$

At this time job could be restarted safely, taking into count phenomenon of casing buckling effect, without exceeding maximum allowable pressure.

\section{Buckling indicators}

Problem of casing buckling during cement displacement, detailed in this paper, has their specific characteristics which could be presented as indicators (Table 5).

FC is the float collar. N\&S means indicator is (necessary and sufficient) specific for this problem. If all N\&S indicators are verified, then problem of casing buckling takes place. These indicators represent the main difference between flash setting and casing buckling. When flash setting occurs, casing weight remains unchangeable and the neutral point out of casing depth (No compressive force from

Fig. 12 5/8 casing cement end of job chart, pressure bleed off

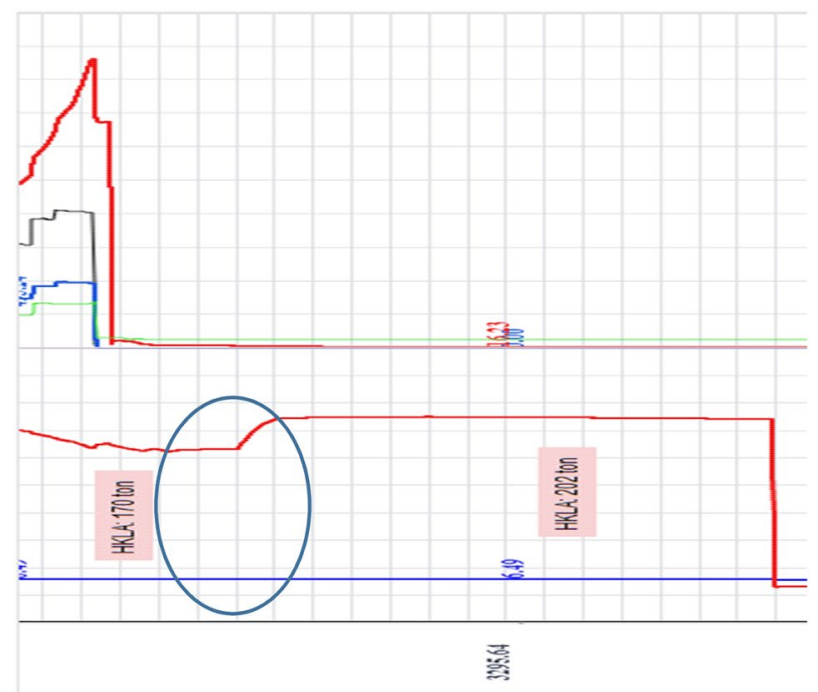

Table 5 Casing buckling indicators

\begin{tabular}{lll}
\hline Indicators & Description & Specification \\
\hline 1-Maximum allowable pressure & Surface pressure superior or equal to $P_{\max }$ & $\mathrm{N} \& \mathrm{~S}$ \\
2-Casing weight & Decrease in casing weight, parallel to pressure rise & $\mathrm{N} \& \mathrm{~S}$ \\
3-Neutral point & Calculated Neutral point is lesser than CSG depth & $\mathrm{N} \& \mathrm{~S}$ \\
4-Casing weight recovered & Casing weight recovered after bleed off & $\mathrm{N} \& \mathrm{~S}$ \\
5-Pressure rise & Pressure rise suddenly as a mechanical reaction & $\mathrm{N}$ \\
6-Cement tagged inside CSG & Cement is tagged fare from FC, Cement left in hole & $\mathrm{N}$ \\
\hline
\end{tabular}


the bottom). $\mathrm{N}$ means the indicator is (necessary but not sufficient) general, and could indicate the apparition of other problems, as flash setting or mechanical problem.

\section{Conclusion}

Using the method presented in this paper lot of cementing critical cases could be avoided. Maximum allowable surface pressure together with additional buckling force, are all used to clarify the buckling occurrence during displacement. Simulation and real cases, confirm usability and merit of the proposed method. More gap between casing depth and hole depth, uses high casing grade and total bleed off then restart displacement, are the recommendations proposed to deal with the problem. Buckling indicators make the analysis and distinguishing buckling from other problems easy task.

Finally, this phenomenon could appear in any cement job when free fall cannot take place, spatially when slurry density is close to mud density.

Results found are:

- Conventional cement job presents equilibrium in terms of hydrostatic pressure between inside and outside casing.

- When free fall phenomenon doesn't exist, disequilibrium of hydrostatic pressure created and buckling may take place.

- Buckling is the generation of an upward compression force, which reduce the influence of tensile.

- As column weight increase the elongation due to tensile effect increases too, and may close the flow itinerary, which leads to pressure rise and stop cement job.

- When cement tag bottom, casing weight decrease progressively and compressive force generated accordingly.

Open Access This article is licensed under a Creative Commons Attribution 4.0 International License, which permits use, sharing, adaptation, distribution and reproduction in any medium or format, as long as you give appropriate credit to the original author(s) and the source, provide a link to the Creative Commons licence, and indicate if changes were made. The images or other third party material in this article are included in the article's Creative Commons licence, unless indicated otherwise in a credit line to the material. If material is not included in the article's Creative Commons licence and your intended use is not permitted by statutory regulation or exceeds the permitted use, you will need to obtain permission directly from the copyright holder. To view a copy of this licence, visit http://creativecommons.org/licenses/by/4.0/.

\section{Appendix A}

See Table 6.

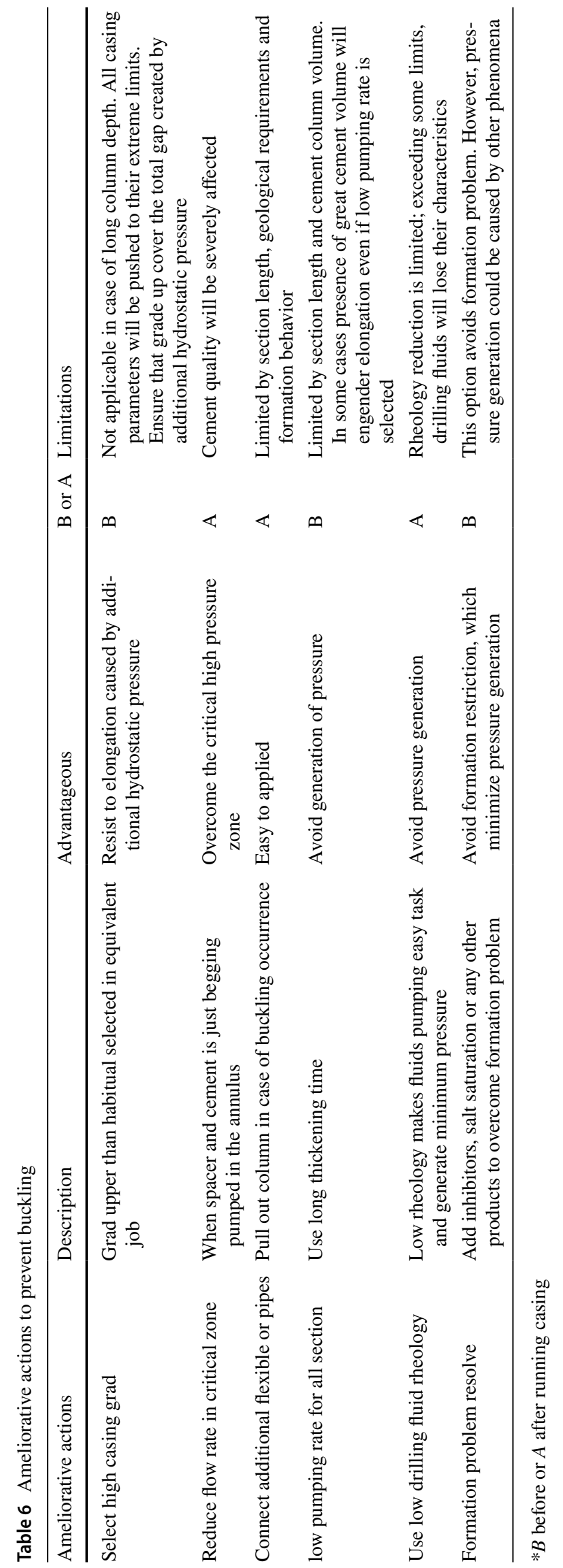




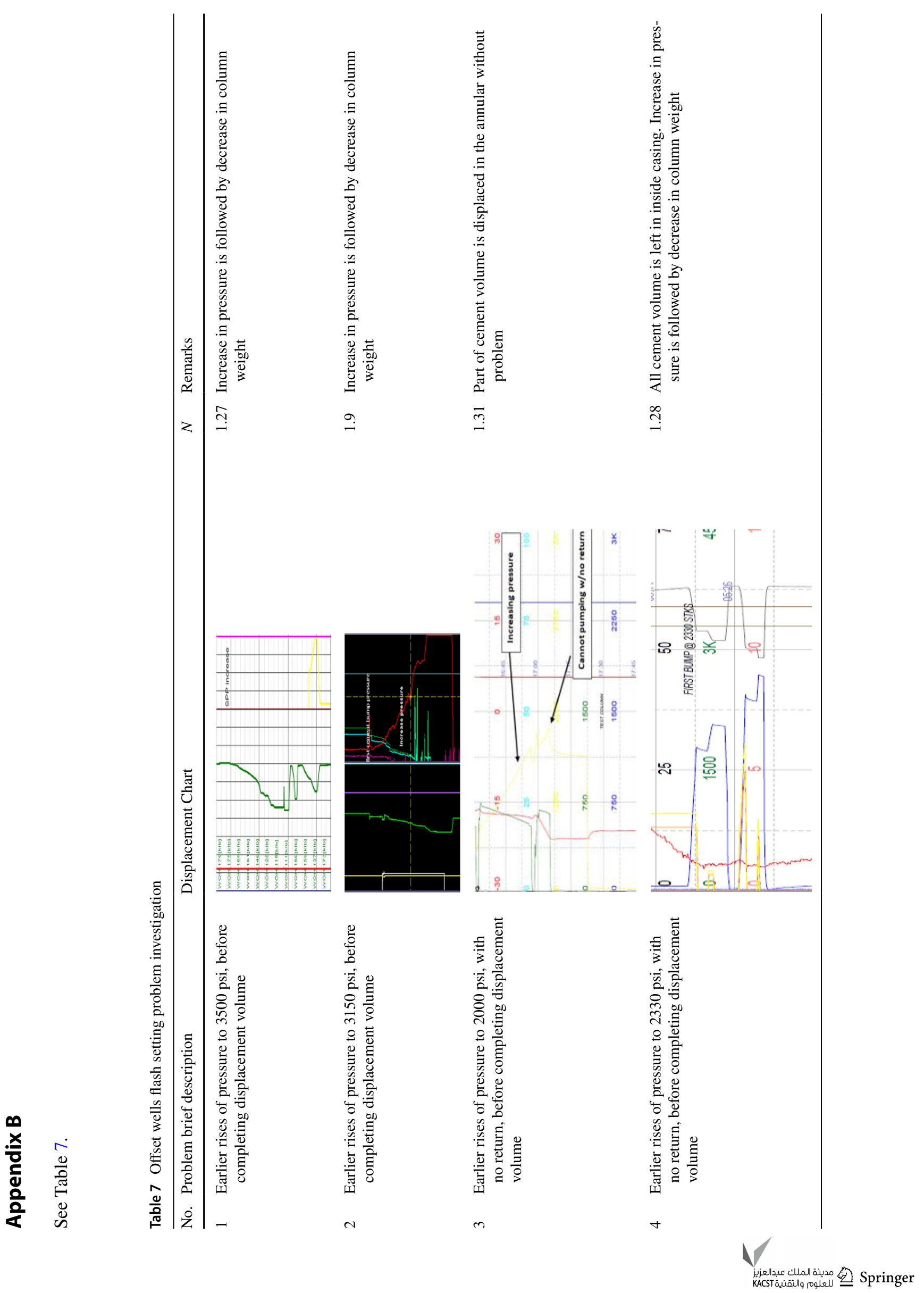




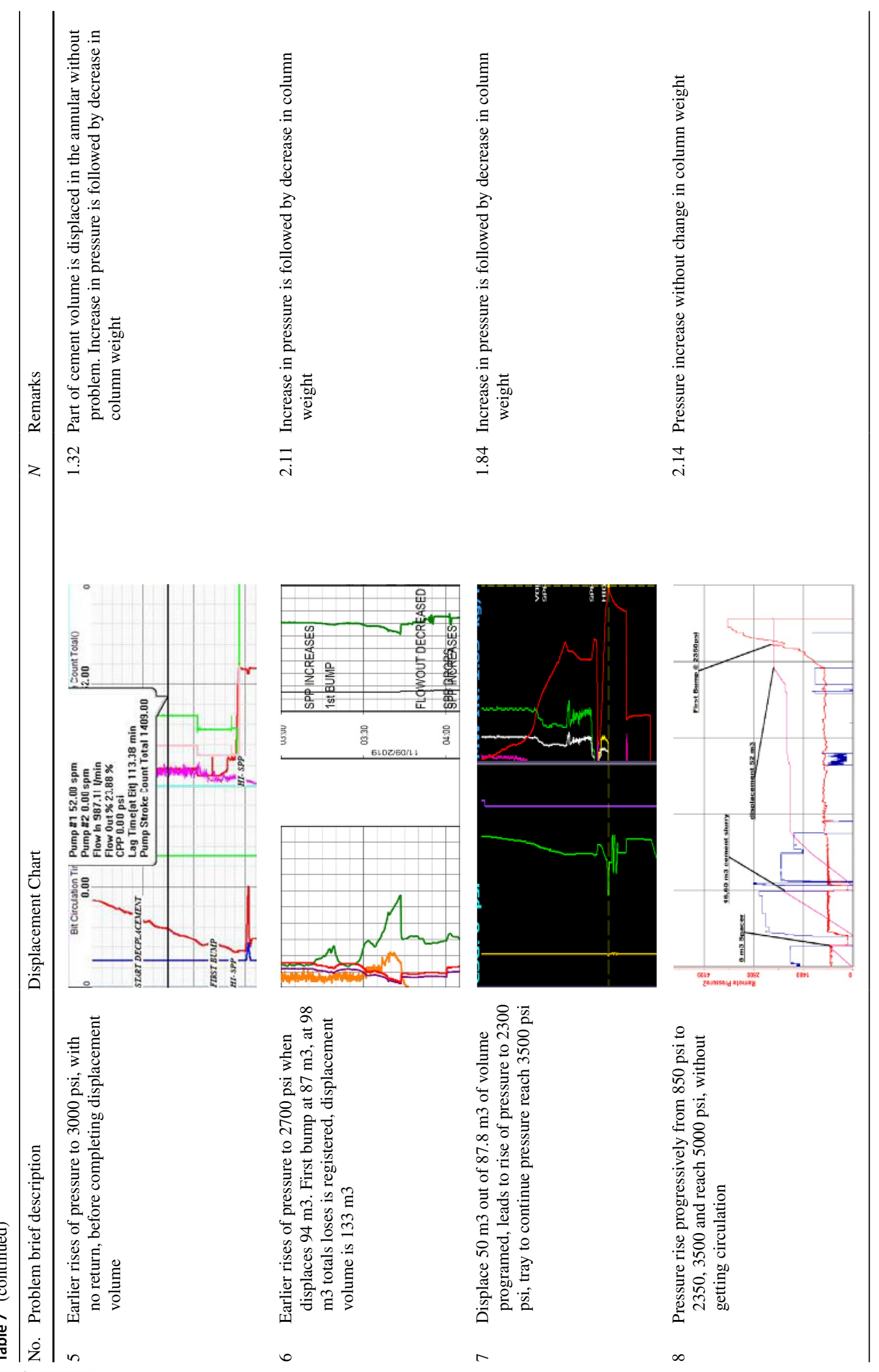




\section{Appendix C}

See Table 8.

Table 8 Casing and slurry characteristics

\begin{tabular}{|c|c|c|c|}
\hline No. & Casing; Mud density sg & Slurry Lead; Tail; Spacer (Volume m3 @ density sg) & $\begin{array}{l}\text { Depth }(\mathrm{m}) \text {; hole section } \\
\text { (in); Free Fall, Y: yeas or } \\
\text { N: no }\end{array}$ \\
\hline 1 & 13 3/8" 68\#; 1.20 & L:42.06@1.32; T:45,58@1.9; S:10@1.30 & 1994; 16"; Y \\
\hline 2 & $95 / 8^{\prime \prime} 47 \# ; 1.80$ & T:34.2@1.9; S:10@1.80 & $2774 ; 12 " 1 / 4 ; \mathrm{N}$ \\
\hline 3 & 13 3/8" 68\#; 1.30 & L:52.29@1.35; T:55,61@1.9; S:10@1.30 & $2400 ; 16^{\prime \prime} ; \mathrm{Y}$ \\
\hline 4 & 13 3/8" 68\#; 1.30 & L:84.82@1.58; T:9,64@1.9; S (Water)10@1 & $1651 ; 16^{\prime \prime} ; \mathrm{N}$ \\
\hline 5 & 13 3/8" 68\#; 1.38 & L:83.38@1.41;T:44,49@1.9; S:10@1.40 & $2485 ; 16^{\prime \prime} ; \mathrm{Y}$ \\
\hline 6 & $95 / 8^{\prime \prime} 47 \# ; 2.27$ & T:45.41@2.32; S:8@2.30 & $3616 ; 12^{\prime \prime} 1 / 4 ; \mathrm{N}$ \\
\hline 7 & $95 / 8^{\prime \prime} 47 \# ; 1.05$ & L:80.1@1.2;T:8,8@1.9; S:6@1.15 & $2324 ; 12 " 1 / 4 ; \mathrm{N}$ \\
\hline 8 & 7" 32\#; 2.25 & T:16.6@2.29; S:9.6@2.27 & $3678 ; 8 " 1 / 2 ; \mathrm{N}$ \\
\hline
\end{tabular}

\section{Appendix D}

See Table 9.

Table 9 Buckling characteristics (Space out is one meters)

\begin{tabular}{|c|c|c|c|c|c|c|}
\hline \multirow[t]{2}{*}{ No. } & \multicolumn{2}{|c|}{ Hydrostatic pressure (psi) } & \multirow{2}{*}{$\begin{array}{l}\text { Surface pressure (psi) } \\
\text { to tag TD }\end{array}$} & \multicolumn{3}{|c|}{ Elongation $(\mathrm{m}) *$} \\
\hline & Inside & Outside & & Before & After & Neat \\
\hline 1 & 4090 & 3400 & 1800 & 1.25 & 2.26 & 1 \\
\hline 2 & 7167 & 7025 & 2400 & 2.16 & 3.17 & 1 \\
\hline 3 & 5090 & 4432.7 & 1400 & 1.79 & 2.79 & 1 \\
\hline 4 & 3527 & 2744 & 2300 & 0.86 & 1.89 & 1 \\
\hline 5 & 5342 & 4872 & 1500 & 1.89 & 2.89 & 1 \\
\hline 6 & 11,752 & 11,659 & 1800 & 3.45 & 4.45 & 1 \\
\hline 7 & 4198 & 3467 & 2300 & 1.74 & 2.75 & 1 \\
\hline 8 & 11,819 & 11,754 & 2600 & 3.59 & 4.61 & 1 \\
\hline
\end{tabular}

*Elongation; $B$ before pumping cement, $A$ when cement is pumped inside casing, $N$ neat elongation

\section{Appendix E}

See Table 10. 
Table 10 Surface pressure, cement program, real job and the occurrence of buckling

\begin{tabular}{llll}
\hline Well no & $\begin{array}{l}\text { Surface Pressure (psi) to } \\
\text { tag bottom (TD) }\end{array}$ & $\begin{array}{l}\text { Program surface pressure (psi), } \\
\text { before reaching the Annulus }\end{array}$ & $\begin{array}{l}\text { Chart surface pressure (psi), } \\
\text { just before reaching the } \\
\text { annulus }\end{array}$ \\
\hline 1 & 1800 & 263 & 2320 \\
2 & 2400 & 100 & 2600 \\
3 & 1400 & 200 & 200 \\
4 & 2300 & 160 & 200 \\
5 & 1500 & 15 & 2973 \\
6 & 1800 & 240 & 2700 \\
7 & 2300 & 100 & 173 \\
8 & 2600 & 600 & 2800 \\
\hline
\end{tabular}

\section{References}

Ahmed A, Mahmoud AA, Elkatatny S, Weiqing Chen (2019) The effect of weighting materials on oil-well cement properties while drilling deep wells. Sustainability 11:6776

Arnfinn N, Naval A (2017) The magic of buoyancy and hydrostaticsbuoyancy and effective forces. Modern Appl Sci 11(12):77

API SPEC 10A/ISO 10426-1 (2010) Specification for cements and materials for well cementing, 24th edn. API, Washington

Bittleston SH, Ferguson J, Frigaard IA (2002) Mud removal and cement placement during primary cementing of an oil well, Laminar nonNewtonian displacements in an eccentric annular Hele-Shaw cell. J Eng Math 43:229-253

Chen YC, Cheatham JB (1990) Wall contact forces on helically buckled tubulars in inclined wells. J Energy Resour Technol 112(2):142-144

Chen YC, Lin YH, Cheatham JB (1990) Tubing and casing buckling in horizontal wells. J PET Technol 42(2):140-191

Chesney Jr. AJ, Garcia J (1969) Load and stability analysis of tubular strings. Paper 69-PET-15, ASME Petroleum echanical Engineering Conference, Tulsa, OK

Clark HC (1987) Mechanical design considerations for fracture-treating down casing strings (includes associated papers 17086 and 17124). SPE Drilling Engineering, vol. 02; no. 2

De Andrade J, Sangesland S, Skorpa R, Todorovic J, Vralstad T (2016) Experimental laboratory setup for visualization and quantification of cement-sheath integrity. SPE Drilling and completion; vol. 31, no 04

Dooply M, Peternell A, Long J (2016) Learning from field measurements: engineering method to implrove cement returns in riserless deepwater jobs. SPE drilling and completion marsh

Hammerlindl DJ (1980) Basic fluid pressure forces on oil well tubulars. J Petrol Technol 34(3):153-159

Jellison MJ, Brock JN (2000) The impact of compression forces on casing-string designs and connectors. SPE Drill Complet 15(4):241-248

Kaarstad E, Aadnoy BS (2011) Theory and application of buoyancy in wells. Mod Appl Sci 5(3):15-32

Kenneth SD (1982) Tubing movement, forces, and stresses in dual-flow assembly installations. Soc Pet Eng J, pp 866-874
Klinkenberg A (1951) The neutral zones in drill pipe and casing and their significance in relation to bucklingand collapse, drilling and production practice. American Petroleum Institute, pp. 64-76

Lavrov A, Torsaeter M (2016) Physics and mechanics of primary well cementing. Springer Briefs in Petroleum Geoscience \& Engineering

Leksir A (2020) Oil well casing flash setting problem causes and identification strategy based on cheese model. J Pet Explor Prod Technol. https://doi.org/10.1007/S13202-020-00882-9

Lubinski A, Althouse WS, Logan JL (1962) Helical buckling of tubing sealed in packers. SPE J Pet Technol 14(6):655-670

Lyons WC, Plisga GJ, Lorenz MD (2016) Standard handbook of petroleum and natural gas engineering (third edition), chapter 4-drilling and well completions. Elsevier

Mitchell RF (1982) Buckling behavior of well tubing: the packer effect. Soc Pet Eng J 22(05):616-624

Mitchell RF (1999) Buckling analysis in deviated wells: a practical method. SPE Drill Compl 14(1):11-20

Mitchel RF (2008) Tubing buckling-the state of the art. SPE Drill Complet 23(4):361-370

Pelipenko S, Frigaard IA (2004) Mud removal and cement placement during primary cementing of an oil well. Part 2; steady-state displacements. J Eng Math 48:1-26

Stair MA, Mcinturff TL (1986) Casing and tubing design considerations for deep sour-gas wells. SPE Drill Eng, pp 221-232

Wang CY (1986) A critical review of the heavy elastica. Int J Mech Sci 28(8):549-559

Wellington C, Antonio L, Ademar PJ (1993) Free-fall-effect calculation ensures better cement-operation design. SPE Drill Eng $8(3): 175-178$

Wu J, Juvkam-Wold HC (1995) Coiled tubing buckling implication in drilling and completing horizontal wells. SPE Drill Complet pp 16-21

Zhang B, Guan Z, Hasan AR, Lu N, Wang Q, Xu Y, Zhang Q, Liu Y (2017) Development and design of new casing to mitigate trapped annular pressure caused by thermal expansion in oil and gas wells. Appl Therm Eng 118:292-298 